\title{
Right Atrial Size and 30-Day Mortality in Normotensive Patients with Pulmonary Embolism
}

José Luís Lobo', Vanessa Zorrilla ${ }^{1}$, José A. Nieto ${ }^{2}$, Vicente Gomez ${ }^{3}$, Ferrán García-Bragado ${ }^{4}$, Teresa Bueso ${ }^{5}$, Andrei Braester ${ }^{6}$, Manuel Monreal $^{7^{*}}$ and Riete investigators ${ }^{8}$

${ }^{1}$ Respiratory Department, Hospital Universitario de Alava, Vitoria, Spain

${ }^{2}$ Department of Internal Medicine, Hospital Virgen de La Luz, Cuenca, Spain

${ }^{3}$ Department of Internal Medicine, Hospital Universitario Ramón y Cajal, Madrid, Spain

${ }^{4}$ Department of Internal Medicine, Hospital de Girona Dr. Josep Trueta, Girona, Spain

${ }^{5}$ Department of Internal Medicine, Hospital Sant Celoni, Sant Celoni, Spain

${ }^{6}$ Department of Haematology, Western Galilee Hospital, Nahariya, Israel

${ }^{7}$ Department of Internal Medicine, Hospital Universitari Germans Trias i Pujol, Badalona, Spain

${ }^{8} \mathrm{~A}$ full list of RIETE investigators is given in the appendix

\begin{abstract}
Background: The role of right atrial (RA) dilatation for predicting mortality in normotensive patients with pulmonary embolism (PE) has not been thoroughly studied.

Methods: We used the RIETE Registry data to evaluate the prognostic value of RA dilatation (visual estimate) on transthoracic echocardiography (ETT) in patients with acute PE presenting with systolic blood pressure levels $\geq 90 \mathrm{~mm} \mathrm{Hg}$.

Results: As of April 2013, 7,677 normotensive patients with acute PE underwent ETT within the first 48 hours. Of these, $2,268(29.5 \%)$ had RA dilatation. At 30 days, 212 patients $(2.76 \%)$ died, of whom $59(0.77 \%)$ died of confirmed PE. Patients with RA dilatation had a 6 -fold higher rate of fatal PE $(1.85 \%$ vs. $0.31 \%$; odds ratio [OR]: $5.98 ; 95 \% \mathrm{Cl}$ : $3.44-10.8)$ and a 2-fold higher all-cause mortality (4.32\% vs. 2.11\%; OR: 2.10; $95 \%$ Cl: 1.59-2.76) compared with those without RA dilatation. On multivariable analysis, RA dilatation independently predicted fatal PE (relative risk [RR]: 3.71 ; 95\% Cl: 1.68-8.17), while right ventricle hypokinesis did not (RR: $1.36 ; 95 \% \mathrm{Cl}: 0.66-2.80$ ).
\end{abstract}

Conclusions: Among normotensive patients with acute PE, RA dilatation on ETT independently predicted fatal $\mathrm{PE}$ at 30 days.

Keywords: Echocardiography; Right atrial dilatation; Pulmonary embolism; Mortality; Prognosis

\section{Introduction}

In patients with pulmonary embolism (PE), early mortality rates range from over $50 \%$ in those initially presenting with cardiogenic shock to less than $5 \%$ in those with systolic blood pressure (SBP) levels over $90 \mathrm{~mm} \mathrm{Hg}$ [1-6]. Based on risk profiles, some patients with acute $\mathrm{PE}$ may require hospitalization or even immediate recanalization of the occluded pulmonary arteries with thrombolytic therapy or surgery, while others may safely undergo treatment at home and avoid hospital admission [7-10]. One area of controversy focuses on the extension of the indication for thrombolytic therapy to a subgroup of patients who appear stable at presentation but have impending right ventricular failure and a high risk of PE-related death. Thus, a major challenge is the identification of potential candidates for thrombolytic therapy by a simple, rapid, and non-invasive method.

Transthoracic echocardiography (TTE) may detect changes occurring in the right ventricle (RV) anatomy and function as a result of PE-associated acute pressure overload, and some of these abnormalities have been associated with outcome in patients with acute PE [11-13]. However, the complex anatomy of the RV and the subjective nature of routinely obtained standard measurements often limit its usefulness in clinical practice, since reliable and reproducible indices of RV dysfunction are difficult to obtain [13-15]. On the contrary, the right atrium (RA) can be clearly seen in the apical view, and its dimensions easily assessed, thus reducing measurement variability $[16,17]$. In patients with idiopathic pulmonary hypertension, RA dilatation has been associated with outcome [18], and recent studies in patients with acute PE have correlated the RA size with the severity of PE assessed with scintigraphy or CT-scan $[16,19]$, However, no studies have thoroughly evaluated the relationship between RA dilatation on TTE and outcome in patients with acute PE.
The RIETE (Registro Informatizado de Enfermedad TromboEmbólica) Registry is an ongoing, multicenter, international (Spain, Italy, France, Israel, Germany, Switzerland, Czech Republic, Macedonia, Portugal and Ireland), observational registry of consecutive patients with symptomatic, objectively confirmed, acute venous thromboembolism (VTE). It started in Spain in 2001, and 6 years later the database was translated into English aimed to expand the Registry to other countries. Data from this registry have been used to evaluate outcomes after acute PE, such as the frequency of recurrent VTE, bleeding and mortality, and risk factors for these outcomes [20-23]. In the current study, we used the RIETE database to compare the 30-day mortality of patients with acute PE presenting with SBP levels $\geq 90 \mathrm{~mm}$ $\mathrm{Hg}$, according to the presence or absence of RA dilatation on TTE at baseline.

\section{Patients and Methods}

\section{Study population}

The study population includes all patients with symptomatic acute PE confirmed by objective tests (ventilation/perfusion lung scintigraphy,

${ }^{*}$ Corresponding author: Manuel Monreal, Department of Internal Medicine Hospital Universitario Germans Trias i Pujol, 08916 Badalona (Barcelona), Spain, Tel: 34-669675313; E-mail: mmonreal.germanstrias@gencat.cat

Received September 25, 2014; Accepted November 17, 2014; Published November 21, 2014

Citation: Lobo JL, Zorrilla V, Nieto AJ, Gomez V, García-Bragado F, et al. (2014) Right Atrial Size and 30-Day Mortality in Normotensive Patients with Pulmonary Embolism. J Pulm Respir Med 4: 218. doi:10.4172/2161-105X.1000218

Copyright: $\odot 2014$ Lobo JL, et al. This is an open-access article distributed under the terms of the Creative Commons Attribution License, which permits unrestricted use, distribution, and reproduction in any medium, provided the original author and source are credited. 
helical CT-scan or pulmonary angiography) who presented with systolic blood pressure levels $\geq 90 \mathrm{~mm} \mathrm{Hg}$ and who underwent TTE within the first 48 hours. All patients provided oral consent to their participation in the registry, according to the requirements of the Ethics Committee within each hospital. The therapeutic approach was left to the decision of the attending physician.

The attending physicians ensured that eligible patients were consecutively enrolled. Data were recorded on to a computer-based case report form at each participating hospital and submitted to a centralized coordinating center through a secure website. Encryption of data was used to enhance confidentiality and security. Data quality was regularly monitored and electronically documented to detect inconsistencies or errors, which were resolved by the local coordinators. Data quality was also periodically monitored by contract research organizations, that compared the medical records with the data in the web. A data audit was performed at periodic intervals. Patient identities remain confidential because they were identified by a unique number assigned by the study coordinating center, which was responsible for all data management.

\section{Study design}

The major outcome was fatal PE at 30 days. The secondary outcome was all-cause mortality at 30 days. Fatal PE, in the absence of autopsy, was defined as any death appearing within 10 days after PE diagnosis (either the initial event or recurrent PE), in the absence of any alternative cause of death. The causes of death were adjudicated by the attending physicians. In case of doubt, the cause of death was adjudicated by the RIETE Adjudication Committee.

\section{Study variables}

The following qualitative TTE parameters were evaluated: RA dilatation (visual estimate), RV hypokinesis (visual estimate) and visualization of thrombus. To measure RA we considered its transverse diameter on the apical four-chamber view. RA dilatation was considered when it was larger than the left atrium. RV hypokinesis was assessed in the apical four-chamber view. In addition, the following quantitative TTE parameters were evaluated in only some patients: RV end-diastolic diameter (on M-mode in the parasternal long-axis view), ratio of right vs. left ventricle end-diastolic diameter (in the apical fourchamber view), tricuspid annular plane systolic excursion (TAPSE), and pulmonary artery pressure (PAP) levels. To obtain TAPSE, the apical four-chamber view was used, and an M-mode cursor was placed through the lateral tricuspid annulus in real time. TAPSE was measured as the total displacement of the tricuspid annulus (centimeters) from end-diastole to end-systole, with values representing the average TAPSE of three to five beats.

The following parameters were also recorded in all patients: baseline characteristics; clinical status including any coexisting or underlying conditions such as chronic heart or lung disease; risk factors for PE; the type and dose of treatment received upon PE diagnosis; and the outcome within the first 30 days.

\section{Treatment and follow-up}

Patients were managed according to the clinical practice of each participating hospital (i.e., there was no standardization of treatment). After diagnosis, all patients were followed-up for at least one month, but a longer follow-up was favored, if possible. At each visit, any signs or symptoms suggesting recurrent $\mathrm{PE}$ or bleeding complications were noted. Each episode of clinically suspected recurrent PE was investigated by repeat lung scanning, helical-CT scan or pulmonary angiography, as appropriate.

\section{Statistical analysis}

The clinical characteristics, treatment strategies and 30-day mortality of patients with or without RA dilatation at baseline were compared. Student's test and Mann-Whitney tests were used to compare continuous variables. Categorical variables were compared using the Fisher exact test. Kaplan-Meier curves were used to estimate mortality over time, with differences between groups assessed with the log-rank test. Cox proportional hazards regression models were used to test for an independent association between RA dilatation and 30-day mortality. A manual backward stepwise approach was used to develop the multivariate models. Statistical significance was defined as a twotailed P-value of $<0.05$ for all analyses. All analyses were completed using the Statistical Package for Social Sciences (SPSS) program (version 15.0 for Windows, SPSS Inc. Chicago, Illinois, USA).

\section{Results}

As of April 2013, 7677 patients with acute PE presenting with SBP levels $\geq 90 \mathrm{~mm} \mathrm{Hg}$ underwent TTE within the first 48 hours. Of these, 2268 patients (29.5\%) had RA dilatation. Patients with RA dilatation were significantly older and more likely had chronic heart failure, chronic lung disease or abnormal creatinine levels than those with no RA dilatation (Table 1). They presented with lower SBP levels, and more likely had hypoxemia and/or electrocardiographic features suggesting acute RV overload (right bundle branch block, S1Q3T3 pattern). Furthermore, patients with RA dilatation more likely had additional TTE findings suggesting right heart overload, such as RV hypokinesis, higher PAP levels, higher RV diameter, or lower TAPSE (Table 1).

\begin{tabular}{|c|c|c|c|}
\hline & Atrial & No atrial & \multirow{2}{*}{$p$ value } \\
\hline & Dilatation & dilatation & \\
\hline Patients, N & 2,268 & 5,409 & \\
\hline \multicolumn{4}{|l|}{ Clinical characteristics } \\
\hline Age (years) & $68 \pm 16$ & $65 \pm 17$ & $<0.001$ \\
\hline Gender (males) & $1,012(45 \%)$ & $2,485(46 \%)$ & 0.289 \\
\hline Cancer & $390(17 \%)$ & $940(17 \%)$ & 0.847 \\
\hline Chronic heart failure & $368(16 \%)$ & $418(7.7 \%)$ & $<0.001$ \\
\hline Chronic lung disease & $382(17 \%)$ & $684(13 \%)$ & $<0.001$ \\
\hline \multicolumn{4}{|l|}{ Physical examination } \\
\hline Heart rate (bpm) & $97 \pm 21$ & $92 \pm 20$ & $<0.001$ \\
\hline Systolic blood pressure levels (mm Hg) & $127 \pm 23$ & $131 \pm 23$ & $<0.001$ \\
\hline \multicolumn{4}{|l|}{ Electrocardiogram } \\
\hline Atrial fibrillation & $305(13 \%)$ & $352(6.5 \%)$ & $<0.001$ \\
\hline Right bundle branch block & $608(29 \%)$ & $749(15 \%)$ & $<0.001$ \\
\hline S1Q3T3 pattern & $624(30 \%)$ & $797(16 \%)$ & $<0.001$ \\
\hline \multicolumn{4}{|l|}{ Laboratory tests } \\
\hline Creatinine levels $>1.2 \mathrm{mg} / \mathrm{dL}$ & $507(22 \%)$ & $845(16 \%)$ & $<0.001$ \\
\hline $\mathrm{PO}_{2}$ levels $(\mathrm{mm} \mathrm{Hg})(\mathrm{N}=5,215)$ & $62 \pm 19$ & $68 \pm 22$ & $<0.001$ \\
\hline Sat $\mathrm{O}_{2}$ levels $(\%)(\mathrm{N}=5,438)$ & $89 \pm 7$ & $92 \pm 6$ & $<0.001$ \\
\hline \multicolumn{4}{|l|}{ Echocardiogram } \\
\hline RA diameter $(\mathrm{cm})(\mathrm{N}=207)$ & $4.3 \pm 1.5$ & $3.3 \pm 1.6$ & $<0.001$ \\
\hline Visualization of thrombus & $105(4.6 \%)$ & $67(1.2 \%)$ & $<0.001$ \\
\hline RV hypokinesis & $1,185(52 \%)$ & $562(10 \%)$ & $<0.001$ \\
\hline PAP levels $(\mathrm{mm} \mathrm{Hg})(\mathrm{N}=4,649)$ & $55 \pm 18$ & $39 \pm 15$ & $<0.001$ \\
\hline RV diameter $(\mathrm{cm})(\mathrm{N}=1,314)$ & $3.9 \pm 1.2$ & $3.0 \pm 0.7$ & $<0.001$ \\
\hline TAPSE $(\mathrm{cm})(\mathrm{N}=1,590)$ & $1.8 \pm 0.8$ & $2.1 \pm 0.9$ & $<0.001$ \\
\hline
\end{tabular}

Bpm: Beats per Minute; PAP: Pulmonary Artery Pressure Levels; TAPSE: Tricuspid Annular Plane Systolic Excursion; RV: Right Ventricle.

Table 1: Clinical characteristics and diagnostic tests of 7,677 normotensive patients with acute PE, according to the presence or absence of atrial dilatation on the echocardiogram. 
Most patients in both subgroups received low-molecular-weight heparin as initial therapy, with no differences between subgroups in mean daily doses, but a higher proportion of patients with RA dilatation received unfractionated heparin ( $23 \%$ vs. $11 \%)$ or thrombolytic therapy (3.4\% vs. $1.0 \%)$ (Table 2 ). Then, most patients in both subgroups switched to vitamin $\mathrm{K}$ antagonists as long-term therapy. In all, 212 patients $(2.76 \%)$ died at 30 days, of whom $59(0.77 \%)$ died of confirmed PE. One in every two patients dying of PE (27 of 59, 46\%), and one in every 5 with all-cause death ( 44 of 212,21\%) died within the first 5 days after PE diagnosis (Figures 1 and 2). PE was the most common cause of death among patients with or without RA dilatation, accounting for $43 \%$ (42 of 98 ) and $15 \%$ (17 of 114) of the deaths, respectively (Table 2).

\begin{tabular}{|c|c|c|c|}
\hline & Atrial & No atrial & \multirow{2}{*}{$\mathrm{p}$ value } \\
\hline & dilatation & dilatation & \\
\hline Patients, N & 2,268 & 5,409 & \\
\hline \multicolumn{4}{|l|}{ Initial treatment } \\
\hline Thrombolytics & 76 (3.4\%) & $53(1.0 \%)$ & $<0.001$ \\
\hline LMWH & $1,630(72 \%)$ & $4,606(85 \%)$ & $<0.001$ \\
\hline Mean LMWH doses (IU/kg/day) & $183 \pm 41$ & $183 \pm 37$ & 0.93 \\
\hline Initial therapy, UFH & $510(23 \%)$ & $586(11 \%)$ & $<0.001$ \\
\hline Inferior vena cava filter & $83(3.7 \%)$ & $164(3.0 \%)$ & 0.155 \\
\hline \multicolumn{4}{|l|}{ Long-term treatment } \\
\hline Vitamin $\mathrm{K}$ antagonists & $1,402(62 \%)$ & $3,285(61 \%)$ & 0.374 \\
\hline LMWH & $721(32 \%)$ & $1,907(35 \%)$ & 0.004 \\
\hline Mean LMWH doses (IU/kg/day) & $173 \pm 49$ & $169 \pm 44$ & 0.048 \\
\hline \multicolumn{4}{|l|}{ 30-day outcome } \\
\hline Overall death & $98(4.32 \%)$ & $114(2.11 \%)$ & $<0.001$ \\
\hline \multicolumn{4}{|l|}{ Causes of death } \\
\hline Pulmonary embolism & $42(1.85 \%)$ & $17(0.31 \%)$ & $<0.001$ \\
\hline Respiratory insufficiency & $9(0.40 \%)$ & $12(0.22 \%)$ & 0.181 \\
\hline Sudden, unexpected & $4(0.18 \%)$ & $5(0.09 \%)$ & 0.327 \\
\hline Bleeding & $5(0.22 \%)$ & $10(0.18 \%)$ & 0.747 \\
\hline Other & $30(1.32 \%)$ & $66(1.22 \%)$ & 0.712 \\
\hline Unknown & $8(0.35 \%)$ & $4(0.07 \%)$ & 0.005 \\
\hline
\end{tabular}

LMWH: low-molecular-weight heparin; IU: international units; UFH: unfractionated heparin.

Table 2: Treatment strategies and 30-day mortality.

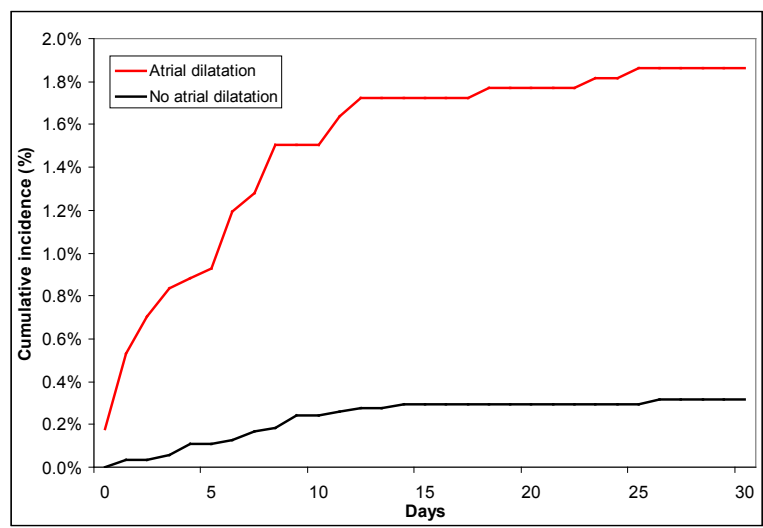

\begin{tabular}{|l|c|c|c|c|c|c|c|}
\hline & \multicolumn{7}{|c|}{ Days } \\
\cline { 2 - 8 } & 1 & 5 & 10 & 15 & 20 & 25 & 30 \\
\hline $\begin{array}{l}\text { RA } \\
\text { dilatation }\end{array}$ & $4(0.2 \%)$ & $\begin{array}{c}21 \\
(0.9 \%)\end{array}$ & $34(1.5 \%)$ & $39(1.7 \%)$ & $40(1.8 \%)$ & $42(1.9 \%)$ & $42(1.9 \%)$ \\
\hline $\begin{array}{l}\text { No RA } \\
\text { dilatation }\end{array}$ & 0 & $6(0.1 \%)$ & $13(0.2 \%)$ & $16(0.3 \%)$ & $16(0.3 \%)$ & $16(0.3 \%)$ & $17(0.3 \%)$ \\
\hline
\end{tabular}

Figure 1: Cumulative mortality due to pulmonary embolism, according to the presence or absence of right atrial dilatation at baseline.

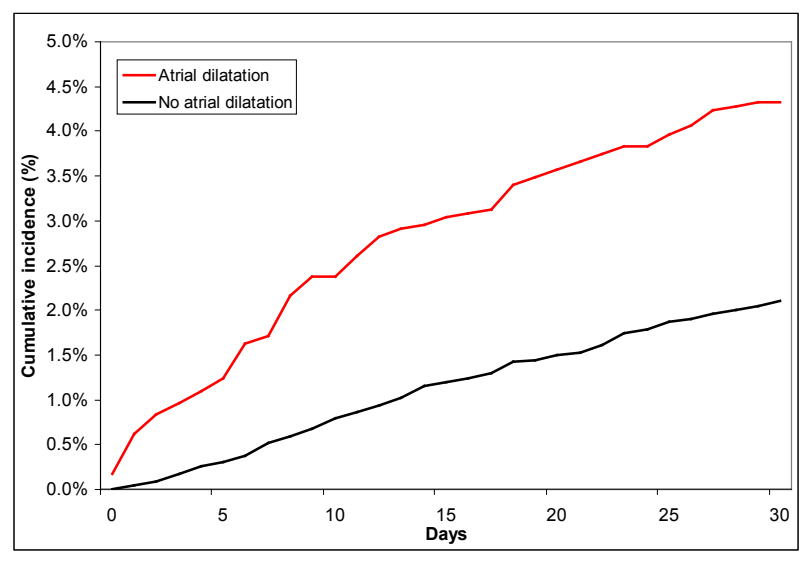

\begin{tabular}{|l|c|c|c|c|c|c|c|}
\hline & \multicolumn{7}{|c|}{ Days } \\
\cline { 2 - 8 } & 1 & 5 & 10 & 15 & 20 & 25 & 30 \\
\hline $\begin{array}{l}\text { RA } \\
\text { dilatation }\end{array}$ & $4(0.2 \%)$ & $28(1.2 \%)$ & $54(2.4 \%)$ & $69(3.0 \%)$ & $81(3.6 \%)$ & $90(4.0 \%)$ & $98(4.3 \%)$ \\
\hline $\begin{array}{l}\text { No RA } \\
\text { dilatation }\end{array}$ & 0 & $16(0.3 \%)$ & $43(0.8 \%)$ & $65(1.2 \%)$ & $81(1.5 \%)$ & $101(1.9 \%)$ & $114(2.1 \%)$ \\
\hline
\end{tabular}

Figure 2: Cumulative all-cause mortality, according to the presence or absence of right atrial dilatation at baseline.

The 30-day rate of fatal $\mathrm{PE}$ in patients with vs. without RA dilatation was: $1.85 \%$ (95\% CI: $1.36-2.47)$ vs. $0.31 \%$ (95\% CI: 0.19 0.49 ), respectively (odds ratio [OR]: $5.98 ; 95 \%$ CI: $3.44-10.8$ ). The 30-day all-cause mortality rate was: $4.32 \%$ (95\% CI: 3.54-5.22) vs. $2.11 \%$ (95\% CI: $1.75-2.52$ ), respectively (OR: 2.10 ; 95\% CI: 1.59 2.76). There were no differences between groups for other causes of death (Table 2). On univariable analysis, patients dying of PE more likely had cancer, chronic heart failure or abnormal creatinine levels, and more likely presented with SBP levels $<100 \mathrm{~mm} \mathrm{Hg}$, tachycardia, tachypnea, atrial fibrillation, hypoxemia, or a right bundle branch block in the electrocardiogram (Table 3). On the TTE exam, patients subsequently dying of PE more likely had RA dilatation, visualization of thrombus, RV hypokinesis, or PAP levels $>35 \mathrm{~mm} \mathrm{Hg}$ (Table 3).

On multivariable analysis, only hypoxemia (risk ratio [RR]: 4.03; 95\% CI: 1.87-8.67) and RA dilatation (RR: 3.71; 95\% CI: 1.68-8.17) significantly predicted fatal $\mathrm{PE}$ at 30 days while RV hypokinesis did not (RR: 1.36 ; 95\% CI: 0.66-2.80), as shown in Table 4. Subsequently, the influence of chronic lung disease or chronic heart disease on this association was analyzed using an interaction analysis, and RA dilatation persisted as an independent predictor for fatal PE.

Then, we compared the inter-individual variability in the measurements of RA and RV in one centre (JLL). The intra-class coefficient of correlation was 0.806 (95\% CI: $0.717-0.868$ ), and in only $16 \%$ of patients ( 14 of 88 ) there was some disagreement for the dilatation of RA (kappa: 0.637). On the contrary, the disagreement for RV dilatation (defined as RVEDD $>3.0 \mathrm{~cm}$ ) appeared in $35 \%$ of patients (32 of 92) (kappa: 0.377).

Finally, all RIETE members were recently asked to quantitatively measure the size of RA diameter. It was obtained in 207 patients, and was $>5 \mathrm{~cm}$ in $32(15 \%)$. Of 3 patients $(1.45 \%)$ who subsequently died of PE, 2 had a diameter $>5 \mathrm{~cm}$ and one had $\leq 5 \mathrm{~cm}$. The hazard ratio of dying of PE in patients with RA diameter $>5 \mathrm{~cm}$ was 11.1 (95\% CI: 1.01-122.7; $\mathrm{p}=0.049$ ). The area under ROC curve was 0.783 (95\% CI: 0.584-0.981). 
Citation: Lobo JL, Zorrilla V, Nietio JA, Gomez V, García-Bragado F, et al. (2014) Right Atrial Size and 30-Day Mortality in Normotensive Patients with Pulmonary Embolism. J Pulm Respir Med 4: 218. doi:10.4172/2161-105X.1000218

Page 4 of 6

\begin{tabular}{|c|c|c|c|c|}
\hline & Fatal PE & No fatal PE & Dead & Alive \\
\hline Patients, N & 59 & 7,618 & 212 & 7,465 \\
\hline \multicolumn{5}{|l|}{ Clinical characteristics } \\
\hline Age $>80$ years & $17(29 \%)$ & $1,739(23 \%)$ & $85(40 \%)^{\ddagger}$ & $1,371(22 \%)$ \\
\hline Gender (males) & $26(44 \%)$ & $3,471(46 \%)$ & $92(43 \%)$ & $3,405(46 \%)$ \\
\hline Cancer & $20(34 \%)^{\dagger}$ & $1,310(17 \%)$ & $97(46 \%)^{\ddagger}$ & $1,233(17 \%)$ \\
\hline Chronic heart failure & $11(19 \%)^{*}$ & $775(10 \%)$ & $47(22 \%)^{\ddagger}$ & $739(9.9 \%)$ \\
\hline Chronic lung disease & $13(22 \%)$ & $1,053(14 \%)$ & $40(19 \%)^{*}$ & $1,026(14 \%)$ \\
\hline \multicolumn{5}{|l|}{ Physical examination } \\
\hline Heart rate $>110 \mathrm{bpm}$ & $24(41 \%)^{\ddagger}$ & $1,651(22 \%)$ & $69(33 \%)^{\ddagger}$ & $1,606(22 \%)$ \\
\hline Respiratory rate $>30 \mathrm{pm}$ & $4(40 \%)^{\dagger}$ & $319(12 \%)$ & $15(27 \%)^{\ddagger}$ & $308(12 \%)$ \\
\hline SBP levels $<100 \mathrm{~mm} \mathrm{Hg}$ & $16(27 \%)^{\ddagger}$ & $809(11 \%)$ & $43(10 \%)^{\ddagger}$ & $782(11 \%)$ \\
\hline \multicolumn{5}{|l|}{ Electrocardiogram } \\
\hline Atrial fibrillation & $10(17 \%)^{*}$ & $647(8.5 \%)$ & $37(18 \%)^{\ddagger}$ & $620(8.3 \%)$ \\
\hline Right bundle branch block & $19(37 \%)^{\dagger}$ & $1,338(19 \%)$ & $55(31 \%)^{\ddagger}$ & $1,302(19 \%)$ \\
\hline $\mathrm{S}_{1} \mathrm{Q}_{3} \mathrm{~T}_{3}$ pattern & $11(22 \%)$ & $1,410(20 \%)$ & $34(19 \%)$ & $1,387(20 \%)$ \\
\hline \multicolumn{5}{|l|}{ Laboratory tests } \\
\hline Creatinine levels $>1.2 \mathrm{mg} / \mathrm{dL}$ & $20(34 \%)^{\dagger}$ & $1,332(18 \%)$ & $64(30 \%)^{\ddagger}$ & $1,288(17 \%)$ \\
\hline $\mathrm{PO}_{2}$ levels $<60 \mathrm{~mm} \mathrm{Hg}(\mathrm{N}=5,215)$ & $28(70 \%)^{\dagger}$ & $2,226(43 \%)$ & $85(58 \%)^{\ddagger}$ & $2,169(43 \%)$ \\
\hline Sat $\mathrm{O}_{2}$ levels $<90 \%(\mathrm{~N}=5,438)$ & $29(76 \%)^{\ddagger}$ & $1,981(37 \%)$ & $86(59 \%)^{\ddagger}$ & $1,924(36 \%)$ \\
\hline \multicolumn{5}{|l|}{ Echocardiogram } \\
\hline Right atrial dilatation & $42(71 \%)^{\ddagger}$ & $2,226(29 \%)$ & $98(46 \%)^{\ddagger}$ & $2,170(29 \%)$ \\
\hline RA diameter $>5.0 \mathrm{~cm}(\mathrm{~N}=207)$ & $2(67 \%)^{*}$ & $30(15 \%)$ & $2(25 \%)$ & $30(15 \%)$ \\
\hline Visualization of thrombus & $9(15 \%)^{\ddagger}$ & $163(2.1 \%)$ & $11(5.2 \%)^{\dagger}$ & $161(2.2 \%)$ \\
\hline Right ventricle hypokinesis & $34(58 \%)^{\ddagger}$ & $1713(23 \%)$ & $77(36 \%)^{\ddagger}$ & $1670(22 \%)$ \\
\hline PAP levels $>35 \mathrm{~mm} \mathrm{Hg}(\mathrm{N}=4,649)$ & $43(96 \%)^{\ddagger}$ & $3262(71 \%)$ & $127(88 \%)^{\ddagger}$ & $3178(71 \%)$ \\
\hline $\mathrm{RV}$ diameter $>3.0 \mathrm{~cm}(\mathrm{~N}=1,314)$ & $6(86 \%)$ & $851(65 \%)$ & $18(56 \%)$ & $839(65 \%)$ \\
\hline TAPSE $<1.6 \mathrm{~cm}(\mathrm{~N}=1,590)$ & $3(60 \%)$ & $581(37 \%)$ & $50(59 \%)^{\dagger}$ & $564(36 \%)$ \\
\hline
\end{tabular}

Comparison between patients with or without the events: $p<0.05 ;{ }^{\dagger} p<0.01 ; \neq p<0.001$.

Bpm: Beats per Minute; SBP: Systolic Blood Pressure Levels; PAP: Pulmonary Artery Pressure Levels; TAPSE: Tricuspid Annular Plane Systolic Excursion; RV: Right Ventricle.

Table 3: Univariable analysis for 30-day mortality.

\begin{tabular}{|c|c|c|c|c|}
\hline & Fatal PE RR $(95 \% \mathrm{Cl})$ & P-Value & Overall death RR $(95 \% \mathrm{Cl})$ & P-Value \\
\hline \multicolumn{5}{|l|}{ Clinical characteristics } \\
\hline Age $>80$ years & & & $1.92(1.36-2.69)$ & $<0.001$ \\
\hline Cancer & & & $3.88(2.79-5.38)$ & $<0.001$ \\
\hline \multicolumn{5}{|l|}{ Physical examination } \\
\hline \multicolumn{5}{|l|}{ Laboratory tests } \\
\hline Sat O2 levels $<90 \%$ & $4.03(1.87-8.67)$ & $<0.001$ & $2.31(1.54-3.48)$ & $<0.001$ \\
\hline \multicolumn{5}{|l|}{ Electrocardiogram } \\
\hline Atrial fibrillation & & & $2.16(1.43-3.27)$ & $<0.001$ \\
\hline \multicolumn{5}{|l|}{ Echocardiogram } \\
\hline Right atrial dilatation & $3.71(1.68-8.17)$ & $<0.001$ & $1.26(0.90-1.77)$ & 0.175 \\
\hline Right ventricle hypokinesis & $1.36(0.66-2.80)$ & 0.407 & $1.34(0.95-1.91)$ & 0.099 \\
\hline
\end{tabular}

Abbreviations: $\mathrm{RR}$, risk ratio; $\mathrm{Cl}$, confidence intervals; $\mathrm{PE}$, pulmonary embolism; bpm, beats per minute.

Variables included in the multivariate analysis for fatal PE: cancer, chronic heart failure, heart rate $>110$ bpm, abnormal creatinine levels, Sat $\mathrm{O}_{2}$ levels $<90 \%$, right atria dilatation, right ventricle hypokinesis and pulmonary artery pressure levels $>35 \mathrm{~mm} \mathrm{Hg}$.

Variables included in the multivariate analysis for all-cause death: age $>80$ years; cancer, chronic heart failure, heart rate $>110$ bpm, systolic blood pressure levels $>100 \mathrm{~mm} \mathrm{Hg}$, atrial fibrillation, right bundle branch block, abnormal creatinine levels, Sat $\mathrm{O}_{2}$ levels $<90 \%$, right atrial dilatation, visualization of thrombus, right ventricle hypokinesis and pulmonary artery pressure levels $>35 \mathrm{~mm} \mathrm{Hg}$.

Table 4: Multivariable analysis for 30-day mortality.

\section{Discussion}

Normotensive patients with acute PE represent a challenge to the clinician. Although their 30-day mortality rate is rather low (ranging from $2.8 \%$ to $6.5 \%$ in recent studies), many of them die of PE, mostly during the first week.2-7 In our series, one in every 36 (2.76\%) such patients died within the first 30 days, and one in every 4 (59 of 212) died of confirmed PE. We hypothesize that some of these deaths might have been prevented if a more accurate therapy (i.e., thrombolytic therapy or insertion of a vena cava filter) would have been applied. In our series, one in every 3 (29.5\%) normotensive patients with PE had RA dilatation, and these patients had a significantly higher risk of dying 
of PE than those with no RA dilatation. Interestingly, the prognostic value of RA dilatation persisted after multivariate adjustment, while RV hypokinesis did not.

During acute PE, there is an increase in pulmonary vascular resistance due to the anatomical obstruction caused by the emboli, release of vasoconstricting agents and reflex hypoxemia [16,24]. The resulting overload induces anatomic changes in the RV that may be identified by TTE, but estimating the volume of a complex structure like the RV is often challenging, not allowing any geometrical assumptions, and diameters or areas are used as surrogate measures in $2 \mathrm{D}$ echocardiography [24]. In fact, visual estimate of RV dilatation was poor in our study (kappa of 0,377). Estimating PAP levels may be also difficult in the absence of tricuspid insufficiency. In fact, one in every 3 patients in our series (3028 of 7677, 39\%) did not have estimated PAP levels.

On the contrary, RA visualization is easier, and its dimensions are reliably obtained on an apical 4-chamber view. However, only a few studies have focused on the prognostic role of RA changes in acute $\mathrm{PE}$ to date. The RA assists in filling the RV by acting as a reservoir for systemic venous return when the tricuspid valve is closed, acting a passive conduit in early diastole when the tricuspid valve is open, and as an active conduit in late diastole during atrial contraction [25]. Thus, it should not be unexpected that RA dilatation reliably predicted outcome.

TTE assessment of the right heart has been largely qualitative until very recently, primarily because of the above mentioned difficulties to assess RV size because of its unusual shape [26,27]. Hence, there are few quantitative data so far for the assessment of RV size and function in patients with acute PE. Current guidelines for the TTE assessment of the right heart, issued in 2010 by the American Society of Echocardiography [12], recommend a gradual shift to more quantitative approaches for the assessment of RV size and function. However, since RIETE started in 2001, most patients had information only on PAP levels and visual estimates on RV hypokinesis or RA dilatation. Only recently we started to gather information on quantitative TTE measurements, such as the TAPSE (which is now available for over 1500 patients) or RA diameter. In future studies we will be able to compare the prognostic value of these new measurements, but our current data suggest that images adequate for RA size estimation should be obtained in patients undergoing evaluation for acute PE.

Our study has important limitations. First, only one in every 3 patients with acute PE in RIETE underwent TTE, and this might have biased our findings thus selecting those perceived to be at a higher risk for complications. However, we compared the 30-day mortality rate in patients with and without TTE and found that those not undergoing TTE had a slightly higher mortality: $3.3 \%$ vs. $2.9 \%$. The higher mortality rate in patients with no echocardiogram may likely be due to the higher proportion of patients with advanced cancer, but this would need further analyses. Second, we cannot rule out that some comorbidities leading to increased mortality and RA dilatation (such as chronic lung disease, chronic heart failure or atrial fibrillation) might have influenced the association between RA dilatation and fatal PE. However, the negative interaction analysis suggests that its impact was, if any, minor. Third, the absence of quantitative TTE data is another major limitation, though this has been usual until the recent guidelines from the American Society of Echocardiography [27].

Moreover, visual estimate of RA size (by comparison with LA size) is counterbalanced by the reality that this relation is not uniquely determined by RA size. Patients with LA enlargement might result in a normal RA: LA ratio even though RA size was, in absolute terms, abnormally large. This is the reason why we recently added RA diameter as a new variable into the database: it was measured in 207 patients and those with $>5 \mathrm{~cm}$ diameter had a significantly higher rate of fatal PE. Thus, we think that correlating RA dilatation with outcome in patients with acute PE could serve as an easy non-invasive way of triaging and better treating patients presenting with this condition. Fourth, given the characteristics of RIETE (over 200 hospitals from 12 countries, recruiting patients for 12 years) it was impossible to coordinate the submission of ETT reports to an independent investigator. We had to rely on the local interpretations at contributing centres. Finally, some patients with PE may have died before obtaining TTE, and this may have also biased our results. Strengths of the current analysis include that a large number of patients were enrolled, and that fatal PE and all-cause death are by far the most important outcomes during the treatment of VTE.

In summary, our findings reveal that one in every 3 patients with acute PE and SBP levels $\geq 90 \mathrm{~mm} \mathrm{Hg}$ may have RA dilatation, and that these patients have a significantly higher risk to die of $\mathrm{PE}$ within the first 30 days. In our study, the prognostic value of RA dilatation was superior to that of RV hypokinesis, a more often used but less reproducible measurement.

\section{Author Contributions}

\section{Study concept and design}

JL Lobo, JA Nieto and M Monreal.

\section{Acquisition of data}

Analysis and interpretation of data; statistical analysis: JL Lobo, V Zorrilla, V Gómez, F García-Bragado, JA Nieto, T Bueso, A Braester, M Monreal.

\section{Drafting of the manuscript}

JL Lobo, M Monreal.

\section{Critical revision of the manuscript for important intellectual content}

JL Lobo, V Zorrilla, V Gómez, F García-Bragado, JA Nieto, T Bueso, A Braester, M Monreal.

\section{Study supervision}

Lobo, Nieto, Monreal.

The corresponding author, Manuel Monreal, had full access to all the data in the study and had final responsibility for the decision to submit for publication.

\section{Coordinator of the RIETE Registry}

Dr. Manuel Monreal (Spain)

\section{RIETE Steering Committee Members}

Dr. Hervè Decousus (France)

Dr. Paolo Prandoni (Italy)

Dr. Benjamin Brenner (Israel)

RIETE National Coordinators:

Dr. Raquel Barba (Spain)

Dr. Pierpaolo Di Micco (Italy)

Dr. Laurent Bertoletti (France)

Dr. Sebastian Schellong (Germany)

Dr. Inna Tzoran (Israel)

Dr. Abilio Reis (Portugal)

Dr. Marijan Bosevski (R.Macedonia)

Dr. Henri Bounameaux (Switzerland)

Dr. Radovan Malý (Czech Republic)

RIETE Registry Coordinating Center

S \& H Medical Science Service 


\section{Acknowledgements}

We express our gratitude to Sanofi Spain for supporting this Registry with an unrestricted educational grant. We also express our gratitude to Bayer Pharma AG for supporting this Registry. Bayer Pharma AG's support was limited to the part of RIETE outside Spain, which accounts for a 17, $94 \%$ of the total patients included in the RIETE Registry. We also thank the Registry Coordinating Center $\mathrm{S} \& \mathrm{H}$ Medical Science Service, for their quality control, logistic and administrative support and Prof. Salvador Ortiz, Universidad Autónoma de Madrid and Statistical Advisor S \& H Medical Science Service for the statistical analysis of the data presented in this paper.

\section{References}

1. Goldhaber SZ, Visani L, De Rosa M (1999) Acute pulmonary embolism: clinical outcomes in the International Cooperative Pulmonary Embolism Registry (ICOPER) Lancet 353: 1386-1389.

2. Quinlan DJ, McQuillan A, Eikelboom JW (2004) Low-molecular-weight heparin compared with intravenous unfractionated heparin for treatment of pulmonary embolism: a meta-analysis of randomized, controlled trials. Ann Intern Med 2140: $175-183$.

3. Douketis JD, Kearon C, Bates S, Duku EK, Ginsberg JS (1998) Risk of fatal pulmonary embolism in patients with treated venous thromboembolism. JAMA 279: 458-462.

4. Vanni S, Nazerian P, Pepe G, Baioni M, Risso M, et al. (2011) Comparison of two prognostic models for acute pulmonary embolism: clinical vs. right ventricular dysfunction-guided approach. J Thromb Haemost 9: 1916-1923.

5. Lankeit M, Jiménez D, Kostrubiec M, Dellas C, Hasenfuss G, et al. (2011) Predictive value of the high-sensitive troponin $T$ assay and the simplified pulmonary embolism severity index in hemodynamically stable patients with acute pulmonary embolism. A prospective validation study. Circulation 124: 2716-2724.

6. Sánchez O, Trinquart L, Planquette B, Couturaud F, Verschuren F, et al. (2013) Echocardiography and PESI have independent prognostic role in pulmonary embolism. Eur Respir J 42: 681-688.

7. Buller HR, Decousus H, Gallus A, Gent M, Piovella F, et al. (2003) Subcutaneous fondaparinux versus intravenous unfractionated heparin in the initial treatment of pulmonary embolism. N Engl J Med 349: 1695-1702.

8. Jiménez D, Yusen RD, Otero R, Uresandi F, Nauffal D, et al. (2007) Prognostic models for selecting patients with acute pulmonary embolism for initial outpatient therapy. Chest 132: 24-30.

9. Jaff MR, Archer SL, Cushman M, Goldenberg N, Goldhaber SZ, et al. (2011) American Heart Association Council on Peripheral Vascular Disease; American Heart Association Council on Arteriosclerosis, Thrombosis and Vascular Biology. Management of massive and submassive pulmonary embolism, iliofemoral deep vein thrombosis, and chronic thromboembolic pulmonary hypertension: A scientific statement from the American Heart Association. Circulation 123: 1788-1830.

10. Jiménez D, Aujesky D, Moores L, Gómez V, Lobo JL, et al. (2010) Simplification of the pulmonary embolism severity index for prognostication in patients with acute symptomatic pulmonary embolism. Arch Intern Med 170: 1383-1389.

11. Goldhaber SZ (2002) Echocardiography in the management of pulmonary embolism. Ann Intern Med 136: 691-700.

12. Kucher N, Rossi E, De Rosa M, Goldhaber SZ (2005) Prognostic role of echocardiography among patients with acute pulmonary embolism and a systolic arterial pressure of $90 \mathrm{~mm} \mathrm{Hg}$ or higher. Arch Intern Med 165: 1777-1781.

13. Sanchez O, Trinquart L, Colombet I, Durieux P, Huisman MV, et al. (2008) Prognostic value of right ventricular dysfunction in patients with haemodynamically stable pulmonary embolism: a systematic review. Eur Heart J 29: 1569-1577.

14. Torbicki A, Perrier A, Konstantinides S, Agnelli G, Galiè N, et al. (2008) ESC Committee for Practice Guidelines (CPG). Guidelines on the diagnosis and management of acute pulmonary embolism: the Task Force for the diagnosis and management of acute pulmonary embolism of the European Society of Cardiology (ESC). Eur Heart J 29: 2276-2315.
15. Rudski LG, Wyman W, Lai WW, Afilalo J, Hua L, et al. (2010) Guidelines for the echocardiographic assessment of the right heart in adults: A report from the American Society of Echocardiography endorsed by the European Association of Echocardiography, a registered branch of the European Society of Cardiology, and the Canadian Society of Echocardiography. J Am Soc Echocardiogr 23: 685-713.

16. Chung T, Emmett L, Khoury V, Lau GT, Elsik M, et al. (2006) Atrial and ventricular echocardiographic correlates of the extent of pulmonary embolism in the elderly. J Am Soc Echocardiogr 19: 347-353.

17. Puchalski MD, Williams RV, Askovich B, Minich LL, Mart C, et al. (2007) Assessment of right ventricular size and function: echo versus magnetic resonance imaging. Congenit Heart Dis 2: 27-31.

18. Bustamante-Labarta M, Perrone S, De La Fuente RL, Stutzbach P, De La Hoz $\mathrm{RP}$, et al. (2002) Right atrial size and tricuspid regurgitation severity predict mortality or transplantation in primary pulmonary hypertension. J Am Soc Echocardiogr 15: 1160-1164.

19. Aviram G, Steinvil A, Berliner S, Rosen G, Sosna J, et al. (2011) The association between the embolic load and atrial size in acute pulmonary embolism. Thromb Haemost 9: 293-299.

20. Laporte S, Mismetti P, Décousus H, Uresandi F, Otero R, et al. (2008) Clinica predictors for fatal pulmonary embolism in 15,520 patients with venous thromboembolism: findings from the Registro Informatizado de la Enfermedad TromboEmbolica venosa (RIETE) Registry. Circulation 117: 1711-1716.

21. Lecumberri R, Soler S, Del Toro J, Barba R, Rosa V, et al. (2011) Effect of the time of diagnosis on outcome in patients with acute venous thromboembolism Findings from the RIETE Registry. Thromb Haemost 105: 45-51.

22. Nieto JA, Solano R, Ruiz-Ribó MD, Ruiz-Giménez N, Prandoni $P$, et al (2010) Fatal bleeding in patients receiving anticoagulant therapy for venous thromboembolism. Findings from the RIETE Registry. J Thromb Haemost 8 : 1216-1222.

23. Muñoz-Torrero JF, Bounameaux H, Pedrajas JM, Lorenzo A, Rubio S, et al. (2011) Effects of age on the risk of dying from pulmonary embolism or bleeding during treatment of deep vein thrombosis. J Vasc Surg 54: 26S-32S

24. Elliott CG (1992) Pulmonary physiology during pulmonary embolism. Chest 101: 163S-171S.

25. Gaynor SL, Maniar HS, Prasad SM, Steendijk P, Moon MR (2005) Reservoir and conduit function of right atrium: impact on right ventricular filling and cardiac output. Am J Physiol Heart Circ Physiol 288: H2140-2145.

26. Jurcut R, Giusca S, La Gerche A, Vasile S, Ginghina C, et al. (2010) The echocardiographic assessment of the right ventricle: what to do in 2010 ? Eur J Echocardiogr 11: 81-96.

27. Lang RM, Bierig M, Devereux RB, Flachskampf FA, Foster E, et al. (2005) Chamber Quantification Writing Group; American Society of Echocardiography's Guidelines and Standards Committee; European Association of Echocardiography. Recommendations for chamber quantification: A report from the American Society of Echocardiography's Guidelines and Standards Committee and the Chamber Quantification Writing Group, developed in conjunction with the European Association of Echocardiography, a branch of the European Society of Cardiology. J Am Soc Echocardiogr 18: 1440-1463. 